\title{
Is "sustainability" still relevant to food systems, or do we need a new term?
}

\author{
Review by Molly D. Anderson* \\ Middlebury College
}

Review of Routledge Handbook of Sustainable and Regenerative Food Systems, edited by Jessica Duncan, Michael Carolan, and Johannes S. C. Wiskerke. (2020). Routledge. Available as hardcover and eBook; 478 pages. Publisher's website: https://www.routledge.com/Routledge-Handbook-ofSustainable-and-Regenerative-Food-Systems/Duncan-CarolanWiskerke/p/book/9781138608047

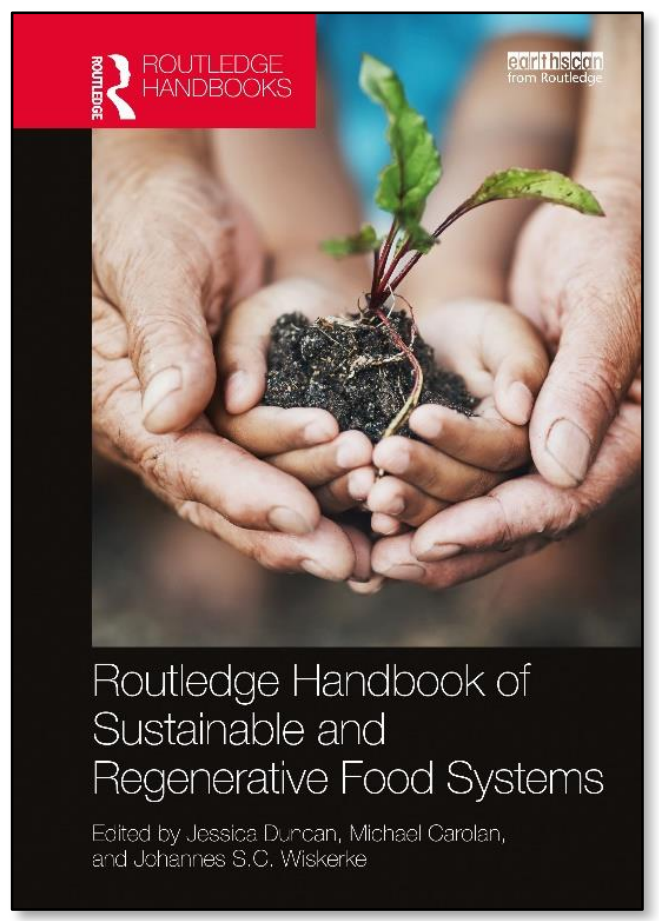

Submitted November 26, 2021 / Published online December 18, 2021

Citation: Anderson, M. D. (2021). Is "sustainability" still relevant to food systems, or do we need a new term? [Book review]. Journal of Agriculture, Food Systems, and Community Development, 11(1), 219-221. https://doi.org/10.5304/jafscd.2021.111.018

Copyright (C) 2021 by the Author. Published by the Lyson Center for Civic Agriculture and Food Systems. Open access under CC-BY license.

$\mathrm{I}$ looked forward to reading the Routledge Handbook of Sustainable and Regenerative Food Systems because I greatly respect the work of its editors and wanted to know how they would organize such a vast topic. It hardly needs repeating that

* Molly D. Anderson, Middlebury College, 202 Robert A. Jones '59 House, Middlebury, VT 05753 USA; MollyA@middlebury.edu

Molly Anderson is the William R. Kenan Jr. Professor of Food Studies at Middlebury College, where she directs the Food Studies Program and teaches about hunger, food sovereignty, agroecology, and food power and justice. She is interested in food system transformations, particularly connections of promising practices and concepts across scales, the role of competing narratives, and the contributions of civil society. today's dominant industrialized food system is destroying biodiversity, degrading soil and water, emitting greenhouse gases, creating products that cause diet-related diseases, erasing traditional farm livelihoods, and destroying farm communities. Despite ample documentation of the problems and wide agreement on their existence, the solutions are much more contentious. What are the alternatives to the destructive industrialized food system, and what is the best trajectory from current practices to a better future? I hoped that this book would provide solid answers.

To some extent, my hopes were met. The Routledge Handbook of Sustainable and Regenerative Food Systems is a smörgåsbord of intriguing topics 
and new perspectives on alternatives to the industrialized food system that links social and ecological aspects. You can dip into any of the chapters and find useful insights into the prospects for creating a better food system. Authors most often come from industrialized countries (Canada, the U.S., E.U., and U.K.). Still, a generous number of contributions come from people working in Latin America (Brazil, Bolivia, Peru, and Costa Rica), Indonesia, Kenya, Tanzania, Australia, India, and Japan. Several chapters deal with Indigenous food systems and are written by people with appropriate backgrounds, i.e., scholars who are Indigenous themselves or are actively engaged with Indigenous communities. The authors are often well-established in their fields, but there are newer scholars (Ph.D. candidates, postdocs, and assistant professors). The editors selected from a wide array of geographical and disciplinary expertise to assemble this cast of contributors, and it is a pleasure to hear from new scholars and regions that are often less well represented in work on sustainable food systems. Each chapter concludes with discussion questions and suggestions for further reading. The index is unusually comprehensive and will help readers find sections of the book dealing with topics that interest them.

My biggest challenge in reading this book is that it lacks a strong organizing framework. The 29 chapters following the introductory chapter by the editors touch on decolonization and Indigenous livelihoods, governance, labor, finance, entrepreneurship, markets, commons, digitalization, food waste, and more. In their introductory chapter, the editors discuss six dynamic and crosscutting principles that are central to advancing regenerative food systems: (1) acknowledging and including diverse forms of knowing and being; (2) taking care of people, animals, and the planet; (3) moving beyond capitalist approaches; (4) commoning the food system; (5) promoting accountable innovations; and (6) long-term planning and rural-urban relations. The editors may have resisted clustering papers and creating subtopics because they wanted to emphasize that these principles are interrelated. Still, clearer signposts throughout the book of which principle is foremost in each chapter would have helped. While each one connects with at least one (and usually several) of the principles suggested by the editors, the flow from one chapter to the next is often unclear.

Many authors grappled with the meaning of regenerative food systems and how the activities that they study fit within it. Some authors (e.g., Sbicca writing about labor, Stephens and Clapp writing about financing, and Ferrando writing about commoning) addressed these questions directly, but others had less connection with them. Given that regenerative food systems still lack a commonly accepted definition, and the concept of regeneration in agriculture has been co-opted to mean many things (just like sustainable agriculture), hearing how diverse authors define it, think it can be enhanced, and understand its relevance to overcoming specific problems with industrialized food systems would have been useful. Chapters that dealt with the connections between regeneration and food system activities or concepts beyond food production were especially interesting, since "regenerative agriculture" in popular media often refers only to food production, as in the recent Kiss the Ground documentary, and does not necessitate other food system shifts.

This book has dual functions: first, encouraging readers to think about the entire food system beyond agriculture, and second, applying concepts and principles of regeneration to various food system activities. The editors see regeneration as a "step beyond sustainability" (p. 9) that better reconciles relations between the social and the environmental and focuses less on maintaining systems or simply doing less damage and more on enhancing the ability of living beings to co-evolve in ways that allow for diversity, complexity, and creativity (p. 4). They rightly point to the unsatisfactory nature of "sustainability," a term that has elicited broad agreement on the United Nations' Sustainable Development Goals yet has been coopted by interests that want to tweak business as usual rather than seek deep structural and social transformations. The Handbook of Regenerative Food Systems might have been a more appropriate title since most chapters connect with this more than with sustainable food systems. However, "sus- 
tainability" remains a compelling and salient goal for many authors, particularly at the global level. Chapters from this book are suitable for undergraduate and graduate audiences and anyone trying to better understand contemporary shifts in ideas for improving food systems. As a whole, the book is an impressive compendium that will help readers understand how the concept of regeneration is infiltrating and re-invigorating thinking about food systems sustainability. It is unfortunate that Routledge has not released a paperback version, since the hardcover price will put the book out of reach of many readers. 